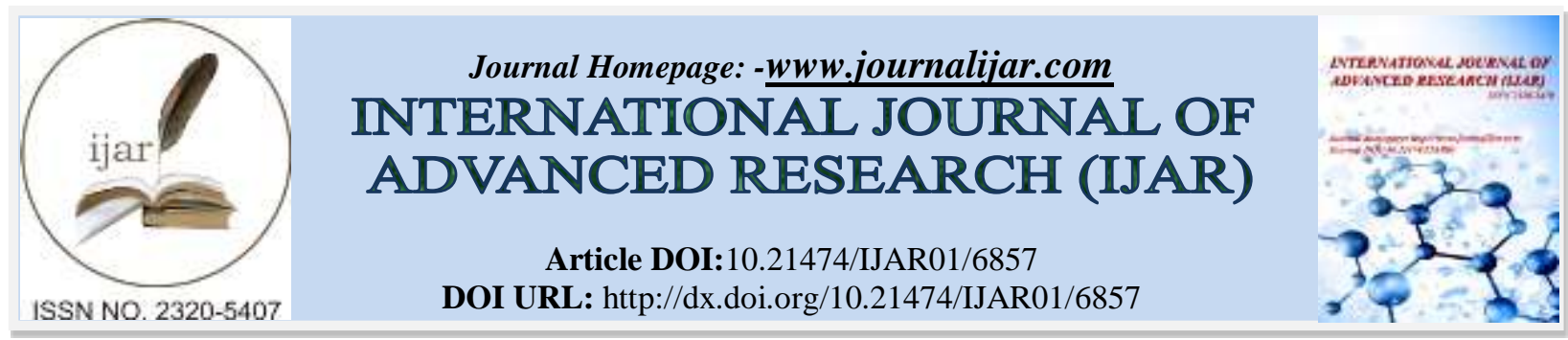

RESEARCH ARTICLE

\title{
POLYCYCLIC-AROMATIC HYDROCARBON (PAHS) IN ENVIRONMENT AND HUMAN HEALTH: A REVIEW.
}

\author{
Ganesh Chandra Kisku ${ }^{1}$, Sindhuja Tripathi ${ }^{1}$ and Abhay Raj ${ }^{2}$. \\ 1. Environmental Monitoring DivisionEnvironmental Microbiology Division. \\ 2. Environmental Toxicology Group, CSIR-Indian Institute of Toxicology Research (CSIR-IITR). \\ 3. Vishvigyan Bhawan, 31-Mahatma Gandhi Marg, Lucknow-226001, UP, India.
}

\section{Manuscript Info}

Manuscript History

Received: 05 February 2018

Final Accepted: 07 March 2018

Published: April 2018

Keywords:-

PAHs, Environmental pollutant,

Toxicity, Health.

\begin{abstract}
Polycyclic aromatic hydrocarbons (PAHs) are a large group of organic compounds with two or more fused benzene rings, which are ubiquitous in nature. PAHs are generated during incomplete combustion during heating or cooking or pyrolysis of organic material. They have a relatively low solubility in water, but are highly lipid soluble and thus readily absorbed from the gastro-intestinal tract of mammals and have a marked tendency for localization in the body fat. World notable public health protecting organizations like IARC, OSHA, EPA, NIOSH and ACGIH considers many of these PAHs are highly toxic, mutagenic and/or carcinogenic properties. US Environmental Protection Agency has promulgated 16 un-substituted PAHs (EPA-PAHs) as priorities pollutants are found in the environmental media (air, soil, water, food and other). This review article offers an overview of PAH's properties, environmental fates, transformations, human exposure, metabolism and covers brief description of different types of toxicities and discuss the magnitude of the human health risks posed by such substances. Benzo[a]pyrene $(\mathrm{BaP})$ is normally present in the environment and the abundance of information on toxicity could be used as biomarker for PAHs toxicity study. The health risk posed by PAHs exposure could be reducing through better management of industrial air pollution.
\end{abstract}

Copy Right, IJAR, 2018,. All rights reserved.

\section{Introduction:-}

Polycyclic aromatic hydrocarbons (PAHs) have received much attention due to their carcinogenic and mutagenic potential and their all over presence in the environment (Flowers et al., 2002). PAHs are a group of organic compounds which have two or more fused aromatic rings. PAHs are originated from mainly anthropogenic processes, particularly from incomplete combustion of organic fuels. PAHs can be present in both particulate and gaseous phases. Once PAHs released into the environment through, natural processes or anthropogenic activities, it spreads widely in the atmosphere. Anthropogenic sources of PAHs like, petroleum products and sources of the incomplete combustion of organic matter in industrial operations, garbage incinerators, power plants, vehicle engines, household wood fires and forest fires. Natural processes, like volcanic eruptions and forest fires, also contribute to an ambient substance of PAHs. PAHs are really multimedia contaminants which happen in whole parts 
of the environment: atmosphere, inland and sea waters, sediments, soils and vegetation (Wild and Jones 1995, Wania and Mackay 1996).

People have so many adverse health effects with long term exposure to high concentration PAHs. PAHs are carcinogenic and genotoxic for the human health. PAHs inhale with particulate matters can cause serious health risk associated with lung cancer, asthma etc. Thus, studies on PAHs in particulate matter (PM), such as $\mathrm{PM}_{10}$ and PM 2.5 in ambient air, has become greater focus of research in recent years. Their occurrence in the air has been increased considerably during the past decades due to the emissions from various industrial processes, energy production from different sources, traffic due to motor vehicular, incineration of refuse, and built-up heating from residential sources. The United States Environmental Protection Agency (USEPA, 2008) monitors 16 priority PAHs in air due to health concerns and name of these PAHs is:

\begin{tabular}{|l|l|l|l|}
\hline (1) Naphthalene & (2)Acenaphthylene, & (3) Acenaphthene & (4) Fluorene, \\
\hline (5) Anthracene & (6) Phenanthrene & (7) Fluoranthene & (8) Pyrene \\
\hline (9) Chrysene & (10) Benz[a]anthracene & (11) Benzo[b]fluoranthene & (12) Mbenzo[k]fluoranthene \\
\hline (13) B[a]P & (14) Indeno[1,2,3-cd]pyrene & (15) Benzo [g,h,i]perylene & (16) Dibenz[a,h]anthracene \\
\hline
\end{tabular}

Particular note is that some of these (naphthalene, chrysene, benzo[b]fluoranthene, benzo[K]fluoranthene, B[a]P, dibenz[a,h]anthracene, dibenzo[a,e]pyrene and dibenzo[a,l] pyrene, and anthanthrene) are reported to be carcinogenic in experimental animals after inhalation or intra tracheal ingestion and this has led increasing concern about the levels of these carcinogens in ambient air.

\section{Chemical and physical properties of PAHs:-}

PAHs formed in different characteristic and also show semi volatile molecules properties to molecules with high boiling points properties. Thus, they found in the gas and also in the particulate phase of ambient air or in mixtures of both phases. As of now near about 500 different types PAHs have been detected in environment, but benzo[a]pyrene $(\mathrm{B}[a] \mathrm{P})$ has given greater attention among the whole PAH family (Bostrom et al. 2002), due to carcinogenic activity. Many of the PAHs in ambient air are carcinogenic (IARC 1983, 1984a, 1984b, 1985, 2010), and a recent reconsideration of their carcinogenic property led to $\mathrm{B}[a] \mathrm{P}$ being upgraded to a group of known human carcinogen(IARC 2010). Thus, there is considerable disquiet about the relationship between PAH disclosure in the ambient air and the potential to contribute to human cancer incidence.

Generally, PAHs are hydrophobic in nature and its solubility in water decreases with increasing molecular weight or the number of fused aromatic rings in PAHs. The high molecular weight PAHs ( $\geq 4$ fused aromatic rings) are less water-soluble, less volatile and are more lipophilic than lower molecular weight PAHs ( $\geq 3$ fused aromatic rings) (Wild and Jones 1995, Wania and Mackay 1996). The 16 PAHs have been used as representative of PAHs to evaluate the anthropogenic pollution levels in sediments and in other environmental components all over the world (Guocheng et al. 2010, Agarwal et al. 2006 and Qiao et al. 2006). PAHs have been listed as priority pollutants by both the US Environmental Protection Agency (EPA) and European Union (EU). The most common sources of exposure to PAHs are tobacco smoke, food, wood, smoke and ambient air (ATSDR 1995). While PAHs can occur naturally, mostly they are originated from anthropogenic processes, such as burning of fuels like wood and other organic substances (Wakeham et al. 1980a,b). PAHs enters the marine environment via industrial discharge, petroleum spills, combustion of fossil fuels and various non-point source inputs such as agriculture, overflow of wastage in urban area and atmospheric deposition (Yunker and Mcdonald 2003, Ke et al. 2009, Cavalcante et al. 2012).

High molecular weight PAHs are much more toxic than those of low molecular weight (Neff et al. 2005). PAHs are ubiquitous organic pollutants that are determined in environment due to the high thermodynamic stability of benzene, their hydrophobic nature (John et al. 2012).

The loads of high molecular weight PAHs in sediment samples is more likely to be transported to the environment due to their increased absorption and degradation resistance properties (Mirza et al. 2012). It has been well established that PAHs have carcinogenic, mutagenic and teratogenic effects on experimental animals (Hoffman and Wynder 1971, Grimmer 1983, Baek et al. 1991, Perera 1997). The organic matter content is considered an important variable related to PAHs pollution of soils (Boehm et al. 2002). Combustion processes and release of un-combusted petroleum products are the two main sources of anthropogenic PAHs found in the environment. In general, parent 
PAHs are largely produced by incomplete combustion of fossil fuels and plant materials or natural digenesis (Yunker et al. 1996). Further, combination of their physico-chemical properties and persistence in the environment make them capable of long-range transport. PAHs possess an increasing capacity, slow degradation rate and their residues are present in the soil, water and sediment even several years after their formation. the concentration of PAHs have been detected in almost all the segments of environment due to their extensive use in past, which have shown potential to biomagnified/accumulated in animal tissue, human blood, adipose tissue and breast milk. PAHs are great environmental and human health concern, because of their harmful effects on invertebrates and mammals including humans through toxicological health risks such as carcinogenic, neurological and hormone disruption to exposed population (Berg et al. 2006).

Concentration ratios of some selected PAHs are considered characteristic of their sources and have widely been used to infer their source nature (Yunker et al. 2002). Due to tendency of PAHs to accumulate in the food chain, their release during dredging operations, episodes of high scouring, or leaching from confined disposal facilities poses a threat to aquatic ecosystems and consequently a potential threat to human health (Tabak et al. 2003). Combustion of different fossil fuels produces PAH emissions with different signature. Thus, it is possible to identify the sources based on their PAH emission "fingerprints" (Yunker et al. 1996). Furthermore, these source signatures can be altered by environmental processes such as photodegradation, volatilization, and solubilization, which act selectively or differentially on individual PAHs species (Simpson et al. 1996, Zhang et al. 2005). Trends of high levels of PAHs in agricultural runoff leading to river contamination have been reported from different parts of the world (Varca 2012, Zhong et al. 2012). In the Ganga river basin, where agriculture predominate the land use activities, manures containing PAHs used in agriculture could easily find their way into the river via runoff.

The low molecular weight (two and three rings) PAHs have a significant acute toxicity, whereas some of the higher molecular weight PAHs are carcinogenic (Watanabe 2001).

\section{Major Sources of PAHs:-}

PAHs get released to the environment through, natural processes and anthropogenic activities (pyrogenic and petrogenic). Anthropogenic sources are petroleum products, incomplete combustion of organic matter in industrial operations, garbage incinerators, power plants, vehicle engines, household wood fires and forest fires. Anthropogenic activities are the main sources of PAHs.

The natural sources of PAHs are volcanic activities like forest fire, domestic fuel discharge and bacterial decompose in organic materials and many other natural process and other sources for formation of PAHs are mainly pyrolytic processes, especially the incomplete combustion of organic materials and fuel during industrial, domestic and other human activities, such as processing of coal and crude oil, combustion of natural gas, heating processes, combustion of refuse material, traffic from vehicle, cooking in house and tobacco smoking, as well as in natural processes like carbonization. Best known PAHs is benzo[a]pyrene $(\mathrm{B}[\mathrm{a}] \mathrm{P})$ and number of heterocyclic aromatic compounds e.g. carbazole and acridine as well as nitro-PAHs, can be generated by incomplete combustion. 


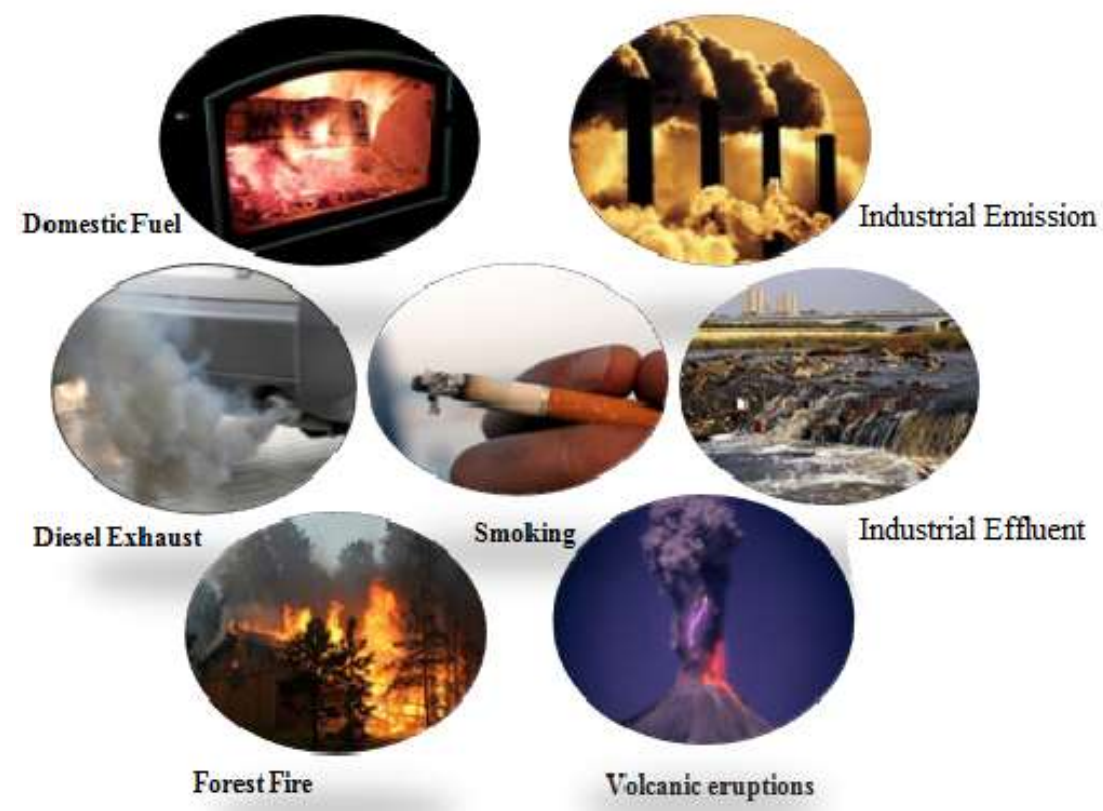

Fig 1:-Major sources of PAHs

Recently, PAH emissions from waste incineration have been investigated in many studies. According to the Italia Agency for Environmental Protection, total EFs of PAHs ranged from 91 to $414 \mu \mathrm{g} / \mathrm{g}$ of waste burned in incinerators of municipal and industrial wastes.

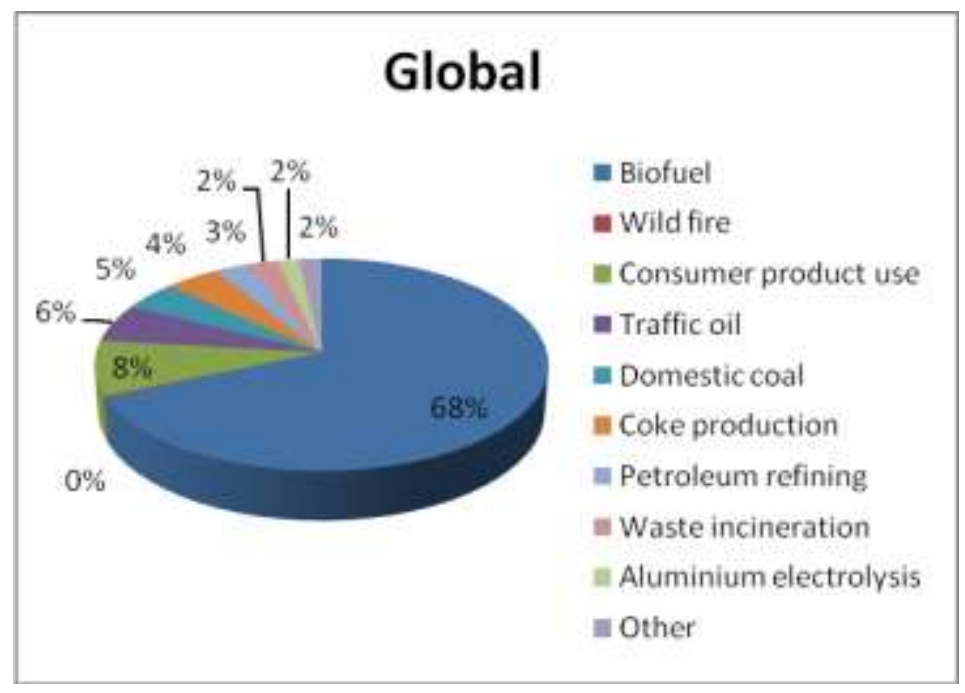



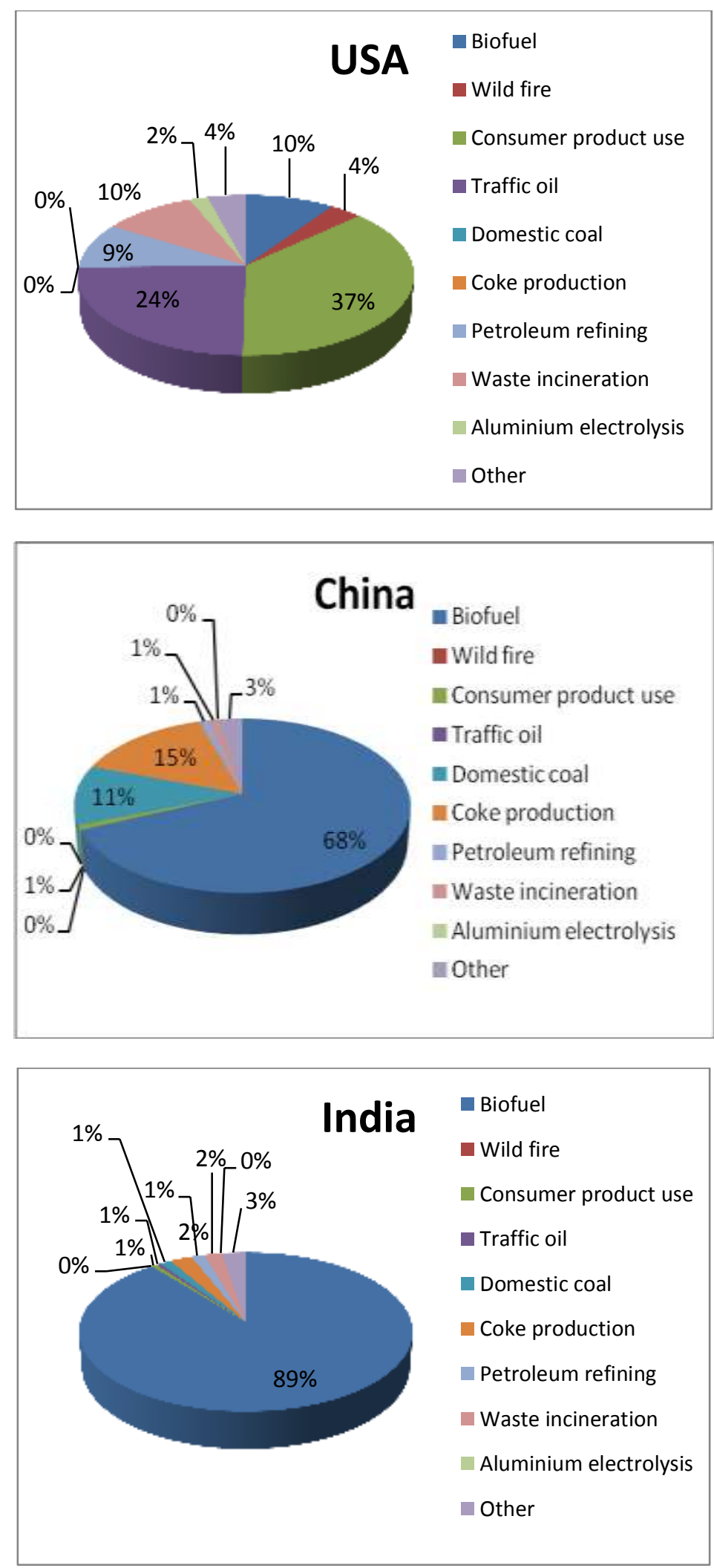

Fig. 2:- According to USEPA, main sources of 16 priority PAHs emissionin (a) Global level, (b) USA, (c) China and (d) India (Zhang and Tao 2009) 


\section{Route of Exposure to PAHs:-}

The exposure of PAHs in human is usually through air, water, soil and food sources occur on a regular basis for most people. Routes of exposure of PAHs include ingestion, inhalation and dermal contact in both occupational and non-occupational settings. Some exposures may involve more than one route simultaneously, affecting the total absorbed dose such as dermal and inhalation exposures from contaminated air. All non-workplace sources of exposure, such as diet, smoking and burning of coal and wood should be taken into consideration.

The main route of exposure to PAHs in the human is from breathing in ambient and indoor air, eating food which containing PAHs, smoking cigarettes or breathing smoke from open fireplaces. A variety of PAHs from tobacco smoke are suspected carcinogenic to human. For non-smokers, the main route of exposure is through food. Some crops such as wheat, rye and lentils may synthesize PAHs or absorb them via water, air or soil (Ciecierska and Obiedzinski 2013). Moreover, intake of PAHs may occur from contaminated soil via ingestion, inhalation or skin exposure and from inhalation of PAH vapours (Wang et al. 2012). Industrial exposure to PAHs may occurs in workers from breathing exhaust fumes such as mechanics, street vendors or motor vehicle drivers and those involved in mining, metal working or oil refining (Armstrong et al. 2004, See et al. 2006). PAHs exposure may be occurs in soil near hazardous waste sites or near areas where coal, wood, gasoline or other products have been burned.

In domestic areas, PAHs are release from tobacco smoke, smoke emitted from wood burning stoves, creosotetreated wood products and other fuel with uncompleted combustion. Also present in some foods, barbecuing, smoking or charring food over a fire greatly increases the amount of PAHs in the food. Other foods that may contain low levels of PAHs include roasted coffee, roasted peanuts, refined vegetable oil, grains, vegetables and fruits. A variety of cosmetics and shampoos are made with coal tar and therefore contain PAHs. The PAH compound naphthalene is present in some mothballs.

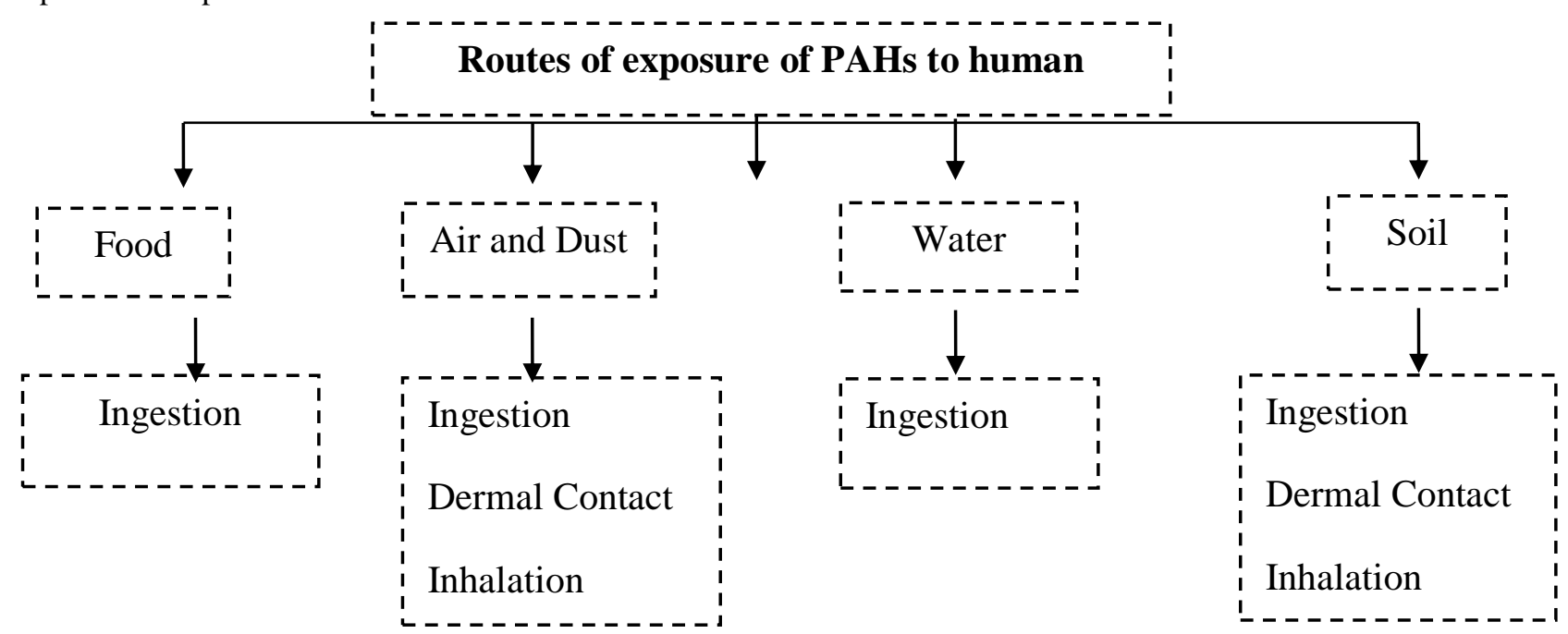

Ecotoxicology of PAHs:-

PAHs are moderately persistent in the environment and can bioaccumulate. PAHs often adsorb to dust particles in atmosphere, where they undergo photo oxidation in the presence of sunlight, especially when they are adsorbed to particles. This oxidation process can break down the chemical over a period of days to week (Santodonato, 1981). Since PAHs are insoluble in water, they are adsorbed on suspended particulates and precipitated in the bottom of lakes and rivers or solubilized in oily substances which may contaminate water. Sediments and soil, mixed microbial population in sediment-water system may degrade some PAHs over a period of weeks to months (ATSDR 2010).

The toxicity of PAHs is affected by metabolism and photo oxidation and they are generally more toxic in the presence of ultraviolet light. It has moderate to high acute toxicity to aquatic life and birds. PAHs in soil are unlikely to exert toxic effect on terrestrial invertebrates, except when soil is contaminated (Peter, 2003). Bioaccumulation has been also shown in terrestrial invertebrates; however PAHs metabolism is sufficient to prevent biomagnifications (Borosky, 1999). The concentration of PAHs found in fish and shellfish are expected to be much higher than in the environment from which they are taken.

Plant can absorb PAHs from soils through their roots and translocate them to other plant parts. Uptake rates are 
governed by concentration, water solubility and their physico-chemical state as well as soil type.

\section{Acute or Short-Term Health Effects:-}

The acute effects of PAHs on human health will depend mainly on the level of exposure viz., length of time, concentration of PAHs during exposure, toxicity of the PAHs and the route of exposure, like via inhalation, ingestion or skin contact. Many other factors may also affect health impacts. These include factors such as preexisting health conditions and age. Short-term exposure to PAHs also has been reported to cause impaired lung function in asthmatics and thrombotic effects in people affected by coronary heart disease. However, it is not known which components of the mixture were responsible for these effects. Currently, there is not a full understanding of the ability of PAHs at ambient concentrations to induce human health effects in the short-term. In contrast, occupational exposures to high levels of pollutant mixtures containing PAHs are known to result in symptoms such as eye irritation, nausea, vomiting, diarrhea, etc. (Unwin et al., 2006). Mixtures of PAHs are also known to cause skin irritation and inflammation. Anthracene, benzo[a]pyrene, naphthalene are direct skin irritants and other skin infections, while anthracene and benzo[a]pyrene are reported to be skin sensitizers, i.e. as cause of an allergic skin response in animals and human.

\section{Chronic or Long Term Health Effects:-}

Industrial workforce are exposed to mixtures of PAHs and other work place chemicals, they suffer from many health related illness such as an increased risk of skin, lung, bladder and gastro-intestinal cancers have been reported (Olsson et al., 2010). Even at low levels long term exposure to some PAHs viz., pyrene and BaP has been identified as the cause of cancer in laboratory animals (Diggs et al., 2011). Toxic kinetics study on animal has also shown adverse reproductive and developmental effects from PAHs exposure as such effects have not usually been detected in humans (Wells et al., 2010).

Repeated skin contact to the PAH naphthalene may result in irritation and redness of skin while breathing or swallowing of naphthalene can cause the breakdown of red blood cells (Srogi, 2007). The harmful effects of PAHs depend on the mechanism of exposure. Unfortunately in almost none of published studies, is there detailed information of human health effects following oral exposure to PAHs. In the majority of studies humans have been occupationally exposed to PAHs via inhalation, while in a few studies the exposure has been via dermal contact. There is little information on human exposure to individual PAH except for some accidental contact with naphthalene. In addition some data from controlled short-term studies of volunteers are available, but the conclusions are not transferable to the human exposure to PAHs via food. All other reports are on exposure to mixtures of PAHs, which also contained other potentially carcinogenic non-PAH chemicals either in occupational or environmental situations, making it difficult to de convolve the effect of the PAHs alone.

Information on the health effects of these mixtures is in practically all cases confined to their carcinogenic potential, based on evidence from a number of epidemiological studies, especially for lung cancer and in some cases cancers of the skin and of the bladder (Armstrong et al., 2002). Moreover, as PAHs have the potential to interfere with hormone systems, they can exert harmful effects on reproduction and immune function. As such, DNA damage induced by PAH exposure has been demonstrated by numerous authors (John et al., 2009; Gunter et al., 2007 and Garcia-Suastegui et al., 2011). Long-term exposure to PAHs is suspected to raise the risks of cell damage via gene mutation and cardiopulmonary mortality (Kuo et al., 2003).

\section{Recommendations for the Protection from PAHS:-}

The International Programme on Chemical Safety offers these general guidelines for protecting human health. Owing to their proven immunotoxic effects, when they cannot be sufficiently reduced, by providing effective personal protection.

Public education about the sources and health effects of exposure to PAH should be improved. Use of unvented indoor fires, as in many developing countries, should be discouraged and they should be replaced by more efficient, well-vented combustion devices. The risk of exposure to PAH from passive smoking should be stressed and measures taken to avoid it. Urban air pollution should be monitored all year round and not only seasonally.

1. Filtration and scrubbing of industrial emissions should be taken.

2. Owing to their proven immune-toxic effects, coal-tar shampoos should be used for anti-dandruff therapy only if no other treatment is available.

3. Due to the immune-toxic and carcinogenic effects of PAH in coke-oven workers, exposure to PAH in 
occupational settings should be eliminated or minimized. This could be done by reducing emissions to the maximum extent. If this not possible, then at least an effective personal protection should be provided.

4. Public awareness and education about the sources and health effects of exposure to PAH should be improved.

5. In many countries, the use of unvented indoor fires should be avoided. They should be replaced by more efficient, well-vented combustion devices.

6. Protection of non-smoker as well as the risk of exposure to PAH from passive smoking should be stressed. Besides, measures should be taken to avoid it.

7. Urban air pollution should be monitored all year round and not only seasonally.

8. Treatment of industrial effluents must be carried out strictly, particularly in the developing countries.

9. The use of catalytic converters and particle traps on motor vehicles should strictly be taken.

\section{Conclusion:-}

Based on past research, it is concluded that polycyclic aromatic hydrocarbons (PAHs) are formed due to incomplete combustion of organic substances. PAHs are classified as highly toxic pollutants and they can cause acute and chronic health problems. Data from a number of occupational health studies suggest that there is an association between occurrence of lung cancer and exposure to PAH compounds. IARC have categorized PAHs as probable carcinogen to human, benz[a]anthracene, benzo[a]pyrene, benzo[b]fluoranthene, benzo[k]fluoranthene, chrysene; as probably carcinogen, [dibenz[a,h]anthracene) benz[a]anthracene and benzo[a]pyrene; and as possibly carcinogen [benzo[a]fluoranthene, benzo[k]fluoranthene and ideno [1,2,3-c,d] pyrene. Benzo[a]pyrene, a probable human carcinogen found in appreciable concentrations in the atmosphere, could be used as a marker of the carcinogenic risk of airborne PAHs. Gaseous pollutants have low molecular weight PAHs with two to three aromatic rings, while high molecular weight PAHs with five or more aromatic rings. Most of heavier PAHs are known to be associated with airborne particulates. Generally, low molecular weight PAHs cause acute effects, but the high molecular weight PAHs, which are resistant to photo degradation can cause more harmful chronic effects like cancer/ mutation or genotoxic. This review article confirms that using wood and agricultural residues for cooking and heating in the rural areas of developing countries are the major risk factor.

\section{Reference:-}

1. Flowers, SH, Rieth, VJ, Cogliano, GL et al (2002) Health assessment of polycyclic aromatic hydrocarbon mixtures: current practices and future direction. Polycycl Aromat Compd, 22: 811- 818 doi: $10.1080 / 10406630290103960$.

2. Wild SR, Jones KC (1995) Polynuclear aromatic hydrocarbons in the United Kingdom 188(1):91-108. PubMed PMID: 15091573.

3. Wania F, Mackay D (1996) Tracking the distribution of persistent organic pollutant. J Environm. Sci. Technol. $30,390$.

4. USEPA (Environmental Protection Agency). (2008) Polycyclic aromatic hydrocarbons (PAHs) EPA fact sheet. Washington, DC: National Center for Environmental Assessment, Of- fice of Research and Development.

5. Bostrom CE, Gerde P, Hanberg A, Jernstrom B, Johansson C, Kyrklund T et al (2002) Cancer risk assessment, indicators, and guidelines for polycyclic aromatic hydrocarbons in the ambient air. Environ. Health Perspect 110:451-488.

6. IARC (1983) Polynuclear aromatic compounds, Part 1, Chemical, environmental and experimental data. IARC Monogr Eval Carcinog Risk Chem Hum,. Dec: 32:1-453

7. IARC (1984) Polynuclear aromatic hydrocarbons, Part 2, carbon blacks, mineral oils (lubricant base oils and derived products) and some nitroarenes. IARC Monogr Eval Carcinog Risk Chem Hum, 33: 1-222. PMID:6590450

8. IARC (1984) Polynuclear aromatic compounds, Part 3, Industrial exposures in aluminium production, coal gasification, coke production and iron and steel founding. IARC Monogr Eval Carcinog Risk Chem Hum 34: 1219

9. IARC (1985) Polynuclear aromatic compounds, Part 4, Bitumens, coal-tars and derived products, shale-oils and soots. IARC Monogr Eval Carcinog Risk Chem Hum, 35: 1-247. PMID:2991123

10. IARC (2010) Some non-heterocyclic polycyclic aromatic hydrocarbons and some related exposures. IARC Monogr Eval Carcinog Risks Hum, 92:1-853. PMID:21141735

11. Guocheng H, Xiaojun L, Fengchao L, Jiayin D, Jianyang G, Shejun C, et al 2010 Organochlorine compounds and polycyclic aromatic hydrocarbons in surface sediment from Baiyangdian Lake, North China: Concentrations, sources profiles and potential risk. J Environmental Sciences 22(2):176-183. 
12. Agarwal T, Khillare PS, Shridha V (2006) PAHs Contamination in bank sediment of the Yamuna River, Delhi, India. Environmental Monitoring and Assessment 123(1): 151-166.

13. Qiao M, Wang CX, Huang SB, Wang DH, Wang ZJ (2006) Composition, sources, and potential toxicological significance of PAHs in the surface sediments of the Meiliang Bay, Taihu Lake, China. J Environment International,. 32(1): 28-33.

14. Agency for Toxic Substances and Disease Registry (ATSDR-1995). Toxicological profile for Polycyclic Aromatic Hydrocarbons (PAHs). Atlanta, GA: U.S. Department of Health and Human Services, Public Health Service.

15. Wakeham SG, Schaffner C, Giger W, (1980a) Polycyclic aromatic hydrocarbons in recent lake sediments. Compounds having anthropogenic origins. J Geochim. Cosmochim. Acta 44, 403-413.

16. Wakeham SG, Schaffner C, Giger W, (1980b) Polycyclic aromatic hydrocarbons in recent lake sediments. Compounds derived from biogenic precursors during early diagenesis. Geochim. Cosmochim.. Acta 44, 415429.

17. Yunker MB, Macdonald RW (2003) Alkane and PAH depositional history, sources and fluxes in sediments from the Fraser River Basin and Strait of Georgia, Canada. J Org. Geochem. 34, 1429-1454.

18. Ke L, Bao W, Chen L, Wong YS, Tam NFY (2009) Effects of humic acid on solubility and biodegradation of polycyclic aromatic hydrocarbons in liquid media and mangrove sediment slurries. J Chemosphere, 76, 11021108.

19. Cavalcante, R.M., F. W. Sousab, R. F. Nascimentoc, E. R. Silveirad andR. B. Viana. 2012. Influence of urban activities on polycyclic aromatic hydrocarbons in precipitation: Distribution, sources and depositional flux in a developing metropolis, Fortaleza, Brazil. The Science of Total Environment 141: 287-292.

20. Neff JM, Stout SA, Gunster DG (2005) Ecological risk assessment of polycyclic aromatic hydrocarbons in sediments: identifying sources and ecological hazard. J Environ Assess Managment Jan;1(1):22-33.

21. John RC, Essien JP, Akpan SB, Okpokwasili GC (2012) Polycyclic aromatic hydrocarbon-degrading bacteria from aviation fuel spill site at Ibeno, Nigeria. Bull Environ Contam Toxicol 88:1014-1019.

22. Mirza R, Mohammady M, Dadoloahi A, Safahieh AR, Savari A, \& Hajeb P (2012) Polycyclic aromatic hydrocarbons in, seawater, sediment and oyster (Saccostrea cucullata) from the Northern part of the Persian Gulf (Bushehr Province). J Water, Air Soil Pollution, 223, 89-198.

23. Hoffman D, Wynder EL (1971) Respiratory carcinogens their nature and precursors. In: Westley B (edn) Identification and measurement of environmental pollutants. Canada' National Research Council, Ottawa, . 916.

24. Grimmer GG (1983) Environmental carcinogens: polycyclic aromatic hydrocarbons chemistry, occurrence, biochemistry, carcinogenicity. CRC Press, Boca Raton, Florida.

25. Baek SO, Goldstone ME, Kirk PWW, Lester JN, Perry R (1991b). Method- ological Aspects of Me asuring Polycyclic Aro- matic Hydrocarbons in the Urban Atmo- sphere, Environ. Technol. 12, 107.

26. Perera FP Environment and cancer: who are susceptible? Science (1997) 278:1068-1073.

27. Boehm PD, Burns WA, Page DS, Bence AE, Mankiewicz PJ, Brown JS, Douglas GS, (2002) Total organic carbon, an important tool in an holistic approach to hydrocarbon source finger printing.Environ Foren 3:243250 .

28. Yunker MB, Snowdon LR, Macdonald RW, Smith JN, Fowler MG, Skibo DN, McLaughlin FA, Danyushevskaya AI, Petrova VI, Ivanov GI (1996) Polycyclic aromatic hydrocarbon composition and potential sources for sediment samples from the Beaufort and Barents Seas. J Environ. Sci. Technol. 30, 1310-1320.

29. Berg V. M, Birnbaum L. S, Denison M, DeVito M, Farland W, Feeley M, Fiedler H, Hakansson H, Hanberg A, Haws L, Rose M, Safe S, Schrenk D, Tohyama C, Tritscher A, Tuomisto J, Tysklind M, Walker N, Peterson RE. 2006. The 2005 World Health Organization reevaluation of human and mammalian toxic equivalency factors for dioxins and dioxin-like compounds. Toxicological Sciences 93(2):223-241.

30. Yunker MB, Macdonald RW, Vingarzan R, Mitchell RH, Goyette D, Sylvestre S (2002) PAHs in Fraser River basin: a critical appraisal of PAH ratios as indicators of PAH source and composition. J Org. Geochem. 33, 48.

31. Tabak HH, JM Lazorchak, L Lei, AP Khodadoust, JE Antia, R Bagchi and MT Suidan (2003) Studies on bioremediation of polycyclic aromatic hydrocarbon contaminated sediments bioavailability, biodegradability and toxicity issues. Environ. Toxicol. Chem. 22: 473-482.

32. Simpson CD, Mosi A, Cullen WR et al. (1996) Composition and distribution of polycyclic aromatic hydrocarbon contamination in surficial marine sediments from Kitimat.

33. Zhang XL, Tao S, Liu WX, Yang Y, Zuo Q, Liu Z (2005) Source diagnostics of polycyclic aromatic hydrocarbons based on species ratios: A multimedia approach. J Environ Sci Technol 39:9109-9114. 
34. Varca LM, (2012) Pesticide residues in surface waters of Pagsanjan-Lumban catchment of Laguna de Bay, Philippines. J Agricultural Water Management, . 106, 35-41. doi:10.1016/j.agwat.2011.08.006.

35. Zhong Y, Carmella SG, Upadhyaya P, Hochalter JB, Rauch D, Oliver A, et al. (2012) Immediate Consequences of Cigarette Smoking: Rapid Formation of Polycyclic Aromatic Hydrocarbon Diol Epoxides. Chemical Research in Toxicology.

36. Watanabe K, (2001) Microorganisms relevant to bioremediation. Current Opinions in Biotechnology, 12, 237-241.

37. Zhang, Y., Tao, S., Shen, H., Ma, J., (2009) Inhalation exposure to ambient polycyclic aromatic hydrocarbons and lung cancer risk of Chinese population. Proceedings of National Academy of Sciences of the United States of America, 106, 21063e21067.

38. Ciecierska M and Obiedzinski MW (2013) Polycyclic aromatic hydrocarbons in vegetable oils from unconventional sources. Food Control, 30(2): 556-56.

39. Wang Y, Tian Z, Zhu H, Cheng Z, Kang M, Luo C, et al. (2012) Polycyclic aromatic hydrocarbons (PAHs) in soils and vegetation near an e-waste recycling site in South China: concentration, distribution, source, and risk assessment. J Sci Total Environ;439: 1 87-93.

40. Armstrong BG, Hutchinson E, Unwin J, Fletcher T, (2004) Lung cancer risk after exposure to polycyclic aromatic hydrocarbons: a review and meta-analysis. Environ Health Perspect 112(9) : 970-978.

41. See SW, Karthikeyan S, Balasubramanian R (2006) Health risk assessment of occupational exposure to particulate-phase polycyclic aromatic hydrocarbons associated with Chinese, Malay and Indian cooking. J Environ Monit 8:3 69-76.

42. Santodonato, (1981) J. Polycyclic Organic Matter, Journal of Environmental Pathology \& Toxicology, 5, 1-364.

43. Peter H. Albers. Petroleum and individual Polycyclic aromatic hydrocarbon in Hoffman DJ, Rattner BA, Buston GA, J. Cairns editors. Handbook of Ecotoxicology. Lewis Publisher. 2003.342, 359.

44. Borosky GL (1999) Theoretical study related to the carcinogenic activity of polycyclic aromatic hydrocarbon derivatives. J Org Chem 64:7738-7744.

45. Unwin J, Cocker J, Scobbie E, Chambers H (2006) An assessment of occupational exposure to polycyclic aromatic hydrocarbons in the UK. Ann Occup Hyg 50(4): 395-403.

46. Diggs DL, Huderson AC, Harris KL, Myers JN, Banks LD, Rekhadevi PV et al. (2011) Polycyclic aromatic hydrocarbons and digestive tract cancers: a perspective. J Environ Sci Health C Environ Carcinog Ecotoxicol Rev; 29:324-57.

47. Wells PG, McCallum GP, Lam KC, et al. (2010) Oxidative DNA damage and repair in teratogenesis and neuro developmental deficits. Birth Defects Res C Embryo Today. ;90:103-109.

48. Srogi K, (2007) Monitoring of environmental exposure to polycyclic aromatic hydrocarbons: a review. J Environ Chem Lett. 5(4):169-95.

49. Armstrong BG, Hutchinson E, Fletcher T, (2002) Cancer risk following exposure to polycyclic aromatic hydrocarbons (PAHs): a meta-analysis. Rep No 068. Sudbury, UK: this health and safety executive. (Available at http://www.hse.gov.uk/research/rrhtm/rr068.htm, 2002, Accessed $21^{\text {st }}$ March 2017).

50. John K, Ragavan N, Pratt MM, Singh PB, Al-Buheissi S, Matanhelia SS et al (2009) Quantification of phase I/II metabolizing enzyme gene expression and polycyclic aromatic hydrocarbon-DNA adduct levels in human prostate. Prostate 69:505-19.

51. Gunter MJ, Divi RL, Kulldorff M, Vermeulen R, Haverkos KJ, Kuo MM, et al. (2007) Leukocyte polycyclic aromatic hydrocarbon-DNA adduct formation and colorectal adenoma. Carcinogenesis 28:1426-9.

52. Garcia-Suastegui WA, Huerta-Chagoya A, Carrasco-Colın KL, Pratt MM, John K, Petrosyan P et al (2011) Seasonal variations in the levels of PAH-DNA adducts in young adults living in Mexico City. Mutagenesis 26:385-91.

53. Kuo CY, Hsu YW, Lee HS (2003) Study of human exposure to particulate PAHs using personal air samplers. J Environ Contam Toxicol; 44:454-9. 